\title{
CENTRAL VENOUS CATHETER-ASSOCIATED FUNGEMIA DUE TO RHODOTORULA MUCILAGINOSA IN A PREMATURE
}

\section{INFANT}

Meltem Polat $^{1}$, Anıl Tapısız ${ }^{2}$, Hasan Tezer ${ }^{2}$

${ }^{1}$ Pamukkale University School of Medicine, Department of Pediatric Infectious Diseases, Denizli, Turkey

${ }^{2}$ Gazi University School of Medicine, Department of Pediatric Infectious Diseases, Ankara, Turkey

\section{Background}

A few cases of Rhodotorula mucilaginosa fungemia have been reported in premature infants. We hereby present a case of central venous catheter (CVC)-associated fungemia due to R.mucilaginosa in a premature infant.

\section{Case Presentation Summary}

A male infant was born weighing 1,450 $\mathrm{g}$ at 31 weeks with cesarean section due to premature rupture of membranes. Therapy including ampicillin and gentamicin was initiated at birth. The patient had a CVC inserted on day 3 for administration of total parenteral nutrition. He developed signs of sepsis and necrotising enterocolitis on day 14 , so empiric treatment with vancomycin, meropenem and fluconazole was started. After a period of clinical improvement lasting $\sim 2$ weeks, the patient's clinical condition deteriorated again, and both peripheral and CVC blood cultures yielded yeasts. Blood culture drawn from the CVC demonstrated positive result 1 hour earlier than the peripheral culture, and the patient diagnosed to have CVC-associated fungemia. The strain was identified as R. mucilaginosa by API 20C AUX (Biomerieux, Marcy l'Etoile, France). Susceptibility test was performed with $E$ test strips, and MICs were the following: $0.25 \mathrm{mg} / \mathrm{L}$ for amphotericin B, over $64 \mathrm{mg} / \mathrm{L}$ for fluconazole, $1 \mathrm{mg} / \mathrm{L}$ for voriconazole, and over $64 \mathrm{mg} / \mathrm{L}$ for micafungin. Vancomycin and meropenem were discontinued, and fluconazole was switched to amphotericin B deoxycolate. The catheter was removed on the sixth day of the antifungal treatment. The patient improved clinically and blood culture became negative. Amphotericin B was discontinued 14 days after the first negative blood culture.

\section{Learning Points/Discussion}

R. mucilaginosa can cause catheterrelated fungemia in premature infants. Correct identification is mandatory for appropriate management, as Rhodotorula spp are resistant to antifungal agents, such as fluconazole and echinocandins. 